\title{
9-cis Retinoic Acid Inhibits Inflammatory Responses of Adherent Monocytes and Increases Their Ability to Induce Classical Monocyte Migration
}

\author{
Ingrid B.M. Kolseth ${ }^{\mathrm{a}, \mathrm{b}}$ Joanna Ågren ${ }^{\mathrm{a}}$, Jibeke Sundvold-Gjerstad $^{\mathrm{b}}$ \\ Staale P. Lyngstadaasc Jacob E. Wang ${ }^{\mathrm{a}}$ Maria K. Dahle ${ }^{\mathrm{a}, \mathrm{b}}$ \\ a Institute for Surgical Research, Oslo University Hospital Rikshospitalet HF, b Institute of Basic Medical Sciences and \\ 'Institute of Clinical Dentistry, University of Oslo, Oslo, Norway
}

\section{Key Words}

Retinoic acid · Monocytes • Inflammation • Cytokines • Chemokines

\begin{abstract}
Patients with vitamin A/retinol deficiency are shown to be prone to infections and to suffer from increased inflammation, effects which can be remedied by vitamin A supplements. We aimed to study how human monocytes from the peripheral venous blood of healthy donors acted within the initial hours after adherence and exposure to bacterial endotoxin in the presence or absence of the 9-cis-isomer of retinoic acid (9cisRA). We found that adherent human monocytes were dominated by the CD14dimCD16+ subtype. Pretreatment with 9cisRA for $1 \mathrm{~h}$ significantly decreased lipopolysaccharide (LPS)-induced mRNA expression and protein release of tumor necrosis factor (TNF) $\alpha$, interleukin (IL)- 6 and chemokine ligands (CCL) 3 and CCL4. In contrast, treatment with 9cisRA rapidly enhanced the production of monocyte chemoattractive protein/CCL2. 9cisRA treatment also led to enhanced migration of classical CD14high monocytes in a transwell in vitro system. We conclude that 9cisRA treatment of human adherent monocytes attenuates the inflammatory responses to LPS and induces the attraction of
\end{abstract}

classical monocytes, a feature which may help explain why supplements administered to vitamin A-deficient patients counteract inflammation and increases the ability to fight infections.

Copyright $\odot 2012$ S. Karger AG, Basel

\section{Introduction}

Aberrant regulation of innate immune responses and uncontrolled cytokine bursts are hallmarks of acute and chronic inflammatory disorders [1]. Dysfunction of the mechanisms controlling inflammation can result in excessive production of inflammatory mediators, organ injury and shock $[2,3]$. Monocytes and other leukocytes adhere in vivo to activated endothelium and are triggered to migrate into inflamed and infected tissue. When the adhered monocytes are brought in contact with infecting pathogens, they serve to mobilize the host response further through proinflammatory cytokine and chemokine release, and this will result in recruitment of additional immune cells. In vitro, monocyte adherence can be induced by a limited period of serum deprivation.

Deficiency in the intake of vitamin A is demonstrated to lead to enhanced production of proinflammatory $\mathrm{cy}$ - 
tokines and impair the ability of rat peritoneal macrophages to ingest and kill bacteria, clearly indicating that vitamin A represents an important factor for controlling human host responses [4-6]. All-trans retinoic acid (atRA), 9-cis retinoic acid (9cisRA) and 13-cis retinoic acid are derivatives of vitamin A [7]. Retinoic acids mainly act on immune cells through two nuclear receptors: the retinoic acid receptors (RARs) which may bind both atRA and 9cisRA, and the retinoid X receptors (RXRs) which bind 9cisRA only $[8,9]$. Several other nuclear receptors known to regulate inflammation act as permissive or nonpermissive heterodimers with RXR, including liver X receptor (LXR), peroxisome proliferator-activated receptors (PPAR) and vitamin D receptor (VDR) [10-12]. In addition, RXR may function as a homodimer [7, 13, 14]. In studies examining the role of 9cisRA in the modulation of inflammation, it is reported that 9cisRA induces the suppression of inflammatory responses in mouse microglia and astrocytes, mouse splenic macrophages and in the human cell line U937 [15-17].

The importance of adherent monocytes in the immediate response to infection motivated us to explore if 9cisRA altered the activity of freshly isolated and adhered human monocytes. We demonstrate that adherent monocytes are dominated by the CD14dimCD16+ subset, and that 9cisRA significantly reduced inflammatory responses to bacterial lipopolysaccharide (LPS) and increased the ability of adherent monocytes to induce migration of CD14highCD16- monocytes.

\section{Materials and Methods}

\section{Materials}

LPS derived from Escherichia coli O6:B26, 9cisRA and atRA were from Sigma-Aldrich (Sigma, St. Louis, Mo., USA). Recombinant human chemokine ligand (CCL)2 was purchased from $\mathrm{Pe}$ proTech (Rocky Hill, N.J., USA).

\section{Human Monocyte Culture}

All human donors gave their informed consent and the study protocol was approved by the institute's committee on human research and thus met the standards of the Declaration of Helsinki [18]. Human adherent monocytes were prepared as previously described [10]. Peripheral venous blood was obtained from healthy volunteers and anticoagulated with heparin $(30 \mathrm{IU} / \mathrm{ml}$; Leo, Ballerup, Denmark). Peripheral blood mononuclear cells were isolated by density gradient centrifugation, using Polymorphprep (Axis-Shield Poc AS, Oslo, Norway) centrifugation according to the manufacturer's instruction. The peripheral blood mononuclear cell fraction was suspended in RPMI1640 (BioWhittaker Europe, Verviers, Belgium) with L-glutamine (2 mM; GIBCO, Grand Island, N.Y., USA) and antibiotics (100 U/ml penicillin and $10 \mu \mathrm{g} /$ $\mathrm{ml}$ streptomycin; GIBCO) without serum, and plated onto 96-well dishes for cytokine assay and 6-well dishes for mRNA isolation. Monocytes were allowed to adhere in the absence of serum for 90 min at $37^{\circ} \mathrm{C} / 5 \% \mathrm{CO}_{2}$ before washing 3 times with medium to remove nonadherent cells. The adherent monocytes were then further cultured in RPMI1640/L-glutamine/antibiotics and 10\% fetal calf serum (GIBCO). Nonadherent monocytes for transwell migration studies were isolated from Buffy coats using Lymphoprep density gradient (Axis Shield Poc), and MACS Monocyte isolation kit II (Miltenyi Biotec, Gladbach, Germany). Monocytes were cultured for $18 \mathrm{~h}$ in RPMI1640/L-glutamine/antibiotics/10\% fetal calf serum prior to migration assay.

\section{Flow Cytometry}

Adherent monocytes grown on UpCell plates (Nunc AS, Roskilde, Denmark), to simplify cell release, and negatively selected nonadherent human monocytes were washed with PBS, blocked for 15 min in PBS with 10\% AB human serum (Invitrogen, Grand Island, N.Y., USA) and human Fc blocking reagent (Miltenyi Biotec), followed by a 30-min incubation with fluorescein isothiocyanate (FITC)-conjugated anti-human CD14, phycoerythrin-conjugated anti-human CD16, or the appropriate isotype controls (all antibodies from ImmunoTools, Friesoythe, Germany). Cells were washed, counted on a FACScan flow cytometer device (FACSCalibur, BD Biosciences), followed by analysis of results with FlowJo 7.5 software (Tree Star Inc., Ashland, Oreg., USA).

\section{Cytokine and Phosphoprotein Assays}

Cytokines released from adherent monocyte cultures were measured in culture supernatants by a multiplex antibody bead kit (Luminex; Biosource, Camarillo, Calif., USA) according to the manufacturer's instructions. The CCL2 assay (fig. 4) was performed using a FlowCytomix Human Basic kit and Human CCL2 Simplex kit (Bender MedSystems) and analyzed by FACSCalibur. Intracellular phosphoproteins in activated monocytes were assayed by the use of Bio-Plex phosphoprotein detection assay (BioRad Laboratories) according to the manufacturer's protocol.

\section{Quantitative PCR}

RNA was isolated from 6-well plates using the E.Z.N.A. Total RNA kit (Omega Bio-Tek, Doraville, Ga., USA). RNase inhibitor was added to the isolated RNA which was stored at $-80^{\circ} \mathrm{C}$ for later analyses. From each sample, $50 \mathrm{ng}$ of total RNA was reverse transcribed using TaqMan reverse transcription reagents (Applied Biosystems, Foster City, Calif., USA). Specific mRNA levels were assessed using the ABI Prism 7900HT (Applied Biosystems) with sequence-specific PCR primers. Real-time PCR was performed with $2 \times$ qPCR Master Mix for SYBR Green (Eurogentec, Liege, Belgium), $300 \mathrm{nM}$ sense and antisense primers (table 1), cDNA and $\mathrm{dH}_{2} \mathrm{O}$ up to $25 \mu \mathrm{l}$. The specificities of all SYBR Green assays were confirmed by melting-point analysis. Levels of $18 \mathrm{~S}$ rRNA (analyzed with 18S predeveloped assay reagents; Applied Biosystems) were used for normalization of target gene expression. All samples were run in triplicate; standard curves were run on the same plate, and the standard curve method was used to calculate the relative gene expression.

\section{Transwell Migration Assay}

Conditioned media from adherent monocytes were harvested and kept at $-20^{\circ} \mathrm{C}$. Prior to the experiments, the conditioned me- 
Table 1. Primers used in the qPCR assays

\begin{tabular}{|c|c|c|}
\hline Target mRNA & Sequence & \\
\hline hTNF $\alpha$ & $\begin{array}{l}\text { forward: } \\
\text { reverse: }\end{array}$ & $\begin{array}{l}\text { 5'-AGGCAGTCAGATCATCTTCTCG-3' } \\
\text { 5'-TGAGGTACAGGCCCTCTGAT-3' }^{\prime}\end{array}$ \\
\hline hIL-6 & $\begin{array}{l}\text { forward: } \\
\text { reverse: }\end{array}$ & 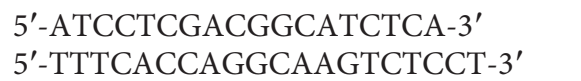 \\
\hline hCCL3/MIP-1 $1 \alpha$ & $\begin{array}{l}\text { forward: } \\
\text { reverse: }\end{array}$ & $\begin{array}{l}\text { 5'-GCATCACTTGCTGCTGACA-3' } \\
\text { 5'-TTTCTGGACCCACTCCTCAC-3' }^{\prime}\end{array}$ \\
\hline hCCL4/MIP-1 $\beta$ & $\begin{array}{l}\text { forward: } \\
\text { reverse: }\end{array}$ & $\begin{array}{l}\text { 5'-AGCACCAATGGGCTCAGA-3' } \\
5^{\prime} \text {-TCACTGGGATCAGCACAGAC-3' }\end{array}$ \\
\hline hCCL2/MCP-1 & $\begin{array}{l}\text { forward: } \\
\text { reverse: }\end{array}$ & 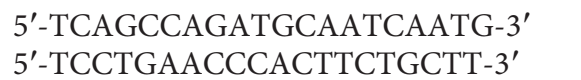 \\
\hline hCXCL8/IL-8 & $\begin{array}{l}\text { forward: } \\
\text { reverse: }\end{array}$ & $\begin{array}{l}\text { 5'-GTGTGAAGGTGCAGTTTTGC-3' } \\
\text { 5'-CTCTGCACCCAGTTTTCCTT-3' }\end{array}$ \\
\hline
\end{tabular}

dium was diluted 2-fold in migration media (RPMI1640/1\%BSA), added to the bottom well of 24-well migration plates (Costar, Lowell, Mass., USA), and allowed to equilibrate at $37^{\circ} \mathrm{C} / 5 \% \mathrm{CO}_{2}$ for $1-2 \mathrm{~h}$. Human nonadherent monocytes $\left(2 \times 10^{5}\right.$ cells $)$ were added to the top chamber in 5 - $\mu \mathrm{m}$-pore size polycarbonate transwell inserts (Costar) and were allowed to migrate for $3 \mathrm{~h}$ in $37^{\circ} \mathrm{C} / 5 \%$ $\mathrm{CO}_{2}$. Recombinant CCL2 (PeproTech) was used as migration control. Cells that had migrated to the lower chamber were collected and 10,000 reference beads (Bangs Laboratories, Fishers, Ind., USA) per sample were added. The migrated cells were counted by flow cytometry (FACSCalibur) and normalized to the internal bead control.

\section{Statistical Analyses}

Data are presented as mean \pm standard deviation (SD). Differences between the groups were analyzed using 1-way analysis of variance (ANOVA) for repeated measures with the NewmanKeuls or the Tukey comparison test. Migration data were analyzed using a paired t test. $\mathrm{p} \leq 0.05$ was considered significant.

\section{Results}

\section{Characterization of Adherent Monocytes}

We wanted to characterize the monocyte subsets present in the adherent monocyte cultures compared with negatively selected monocytes, and performed a CD14/ CD16 flow cytometry analysis. We found that adherent monocyte cultures contained about $60 \%$ of the CD14dimCD16+ monocyte subset whereas only $20 \%$ of the cells were of the main blood monocyte population (CD14high) (fig. 1a). In contrast, CD14dimCD16+ monocytes were nearly absent from the cell population arising from the isolation of 'untouched' monocytes (negative selection, MACS Miltenyi), which was clearly dominated by CD14high cells (70\%) (fig. 1b). Both cultures contained about $20 \%$ of cells that were either CD14dimCD16- or negative for both markers.

\section{9cisRA Pretreatment Alters LPS-Induced Cytokine and Chemokine Release in Monocytes}

In order to explore whether 9cisRA attenuates inflammation, adherent human monocytes were treated with 9cisRA $(0.1$ or $1 \mu \mathrm{M})$ or the solute DMSO (1:1000, control) $1 \mathrm{~h}$ before LPS stimulation $(1 \mu \mathrm{g} / \mathrm{ml})$. Plasma was harvested after $6 \mathrm{~h}$, and a panel of cytokines and chemokines was measured by luminex assay. 9cisRA pretreatment led to a significant reduction of the LPSinduced levels of tumor necrosis factor $\alpha(\mathrm{TNF} \alpha)$ by about $80 \%$ after 6 h (fig. 2a). Also, interleukin (IL)-6 (fig. 2b), IL-10 (fig. 2h), CCL3/macrophage inflammatory protein (MIP)-1 $\alpha$ (fig. $2 c$ ) and CCL4/MIP-1 $\beta$ (fig. 2d) were significantly attenuated in what appears to be a concentration-dependent manner, whereas the CCL2/macrophage chemoattractive protein-1 level was significantly increased (fig. 2e). A trend towards downregulation of only the granulocyte chemoattractant CXCL8/IL-8 (fig. 2f) was observed, indicating that 9cisRA did not strongly affect granulocyte attraction. Other chemokines that were not regulated by 9 cisRA in our assays were CXCL10/IFN- $\gamma$-inducible protein-10, CXCL9/ monokine induced by IFN- $\gamma$, CCL11/eotaxin and CCL5/ RANTES (data not shown). The production of IL-1 $\beta$ seemed not to be affected by 9cisRA stimulation (fig. $2 \mathrm{~g}$ ). Other cytokines tested that were not affected were IL1Ra, IL-2, IL-2R, IL-4, IL-5, IL-7, IL-12, IL-13, IL-15, IL17 , IFN- $\alpha$, IFN- $\gamma$ and granulocyte/macrophage colonystimulating factor (data not shown). In parallel experiments, we also tested the combined effect of 9cisRA 
Fig. 1. Adherent monocytes are enriched for CD14dimCD16+ cells. Flow cytometry analysis of adherent monocytes (a) and negatively selected nonadherent monocytes (b). Representative FACS dot blots and graphs of percentage counts (mean \pm SD) from 3 donors are shown.
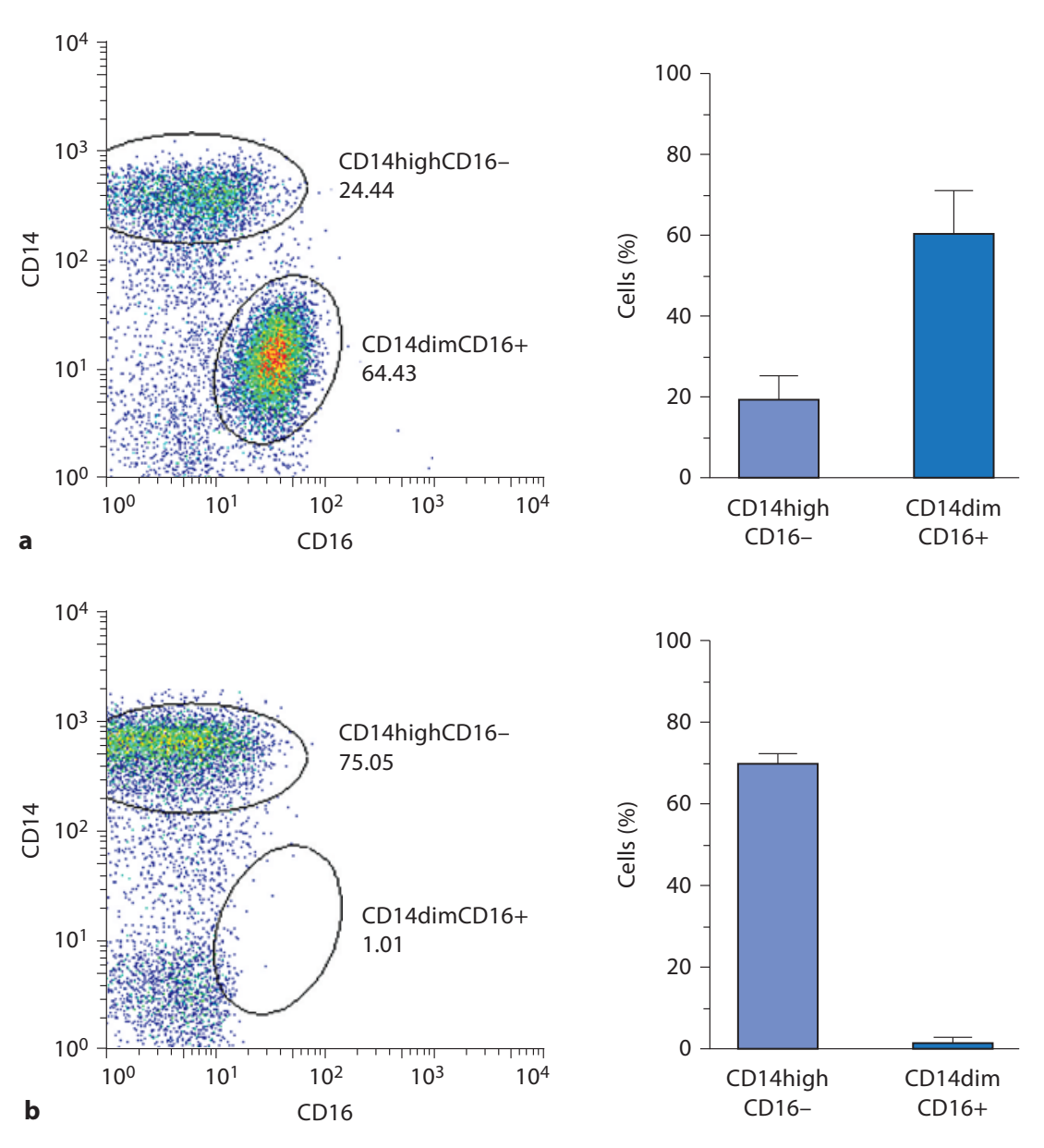

(1 $\mu \mathrm{M})$ and the LXR agonist GW3965 (0.3 $\mu \mathrm{M}$, GlaxoSmithKline). The LXR agonist did not have any additional effect on cytokine expression in combination with 9cisRA (data not shown).

\section{9cisRA Pretreatment Alters LPS-Induced Cytokine mRNA Levels}

To study if the 9cisRA-mediated suppression and upregulation of cytokine and chemokine release was due to transcriptional or posttranscriptional mechanisms, we isolated RNA from adherent monocytes treated with LPS for $2 \mathrm{~h}$ with or without 9cisRA pretreatment. By quantitative RT-PCR, we measured whether mRNA levels of TNF $\alpha$, IL-6, CCL3, CCL4 and CXCL8 were affected by 9cisRA treatment. LPS-induced TNF $\alpha$, IL-6, CCL3 and CCL4 mRNA were significantly downregulated by pretreatment with 9cisRA (fig. 3a-d), whereas the mRNA level of CCL2 was significantly upregulated (fig. 3e). The
mRNA level of CXCL8 (fig. 3f) was not affected by pretreatment with 9 cisRA.

\section{No Effects of 9cisRA Were Found on Phosphoproteins Involved in LPS Signaling}

Knowing that 9cisRA modulates inflammatory responses to LPS at the mRNA level, we questioned if there were changes in the activation of LPS-induced phosphorylation of protein kinases upstream of nuclear factor $(\mathrm{NF}) \kappa \mathrm{B} /$ activation protein-1. Adherent monocytes pretreated for $1 \mathrm{~h}$ with 9cisRA followed by LPS for $20 \mathrm{~min}$ were analyzed for phosphoproteins by Bio-Plex assay. Our results (fig. 4) did not indicate that 9cisRA had any effects on the activation of extracellular signal-regulated kinase (ERK), inhibitor of nuclear factor $\kappa \mathrm{B}$ (ІкB), c-Jun $\mathrm{N}$-terminal kinase (JNK) or $\mathrm{p} 38$ mitogen-activated protein kinase (MAPK) within the first 20 min of activation (fig. 4). There was similarly no effect on signaling kinases 


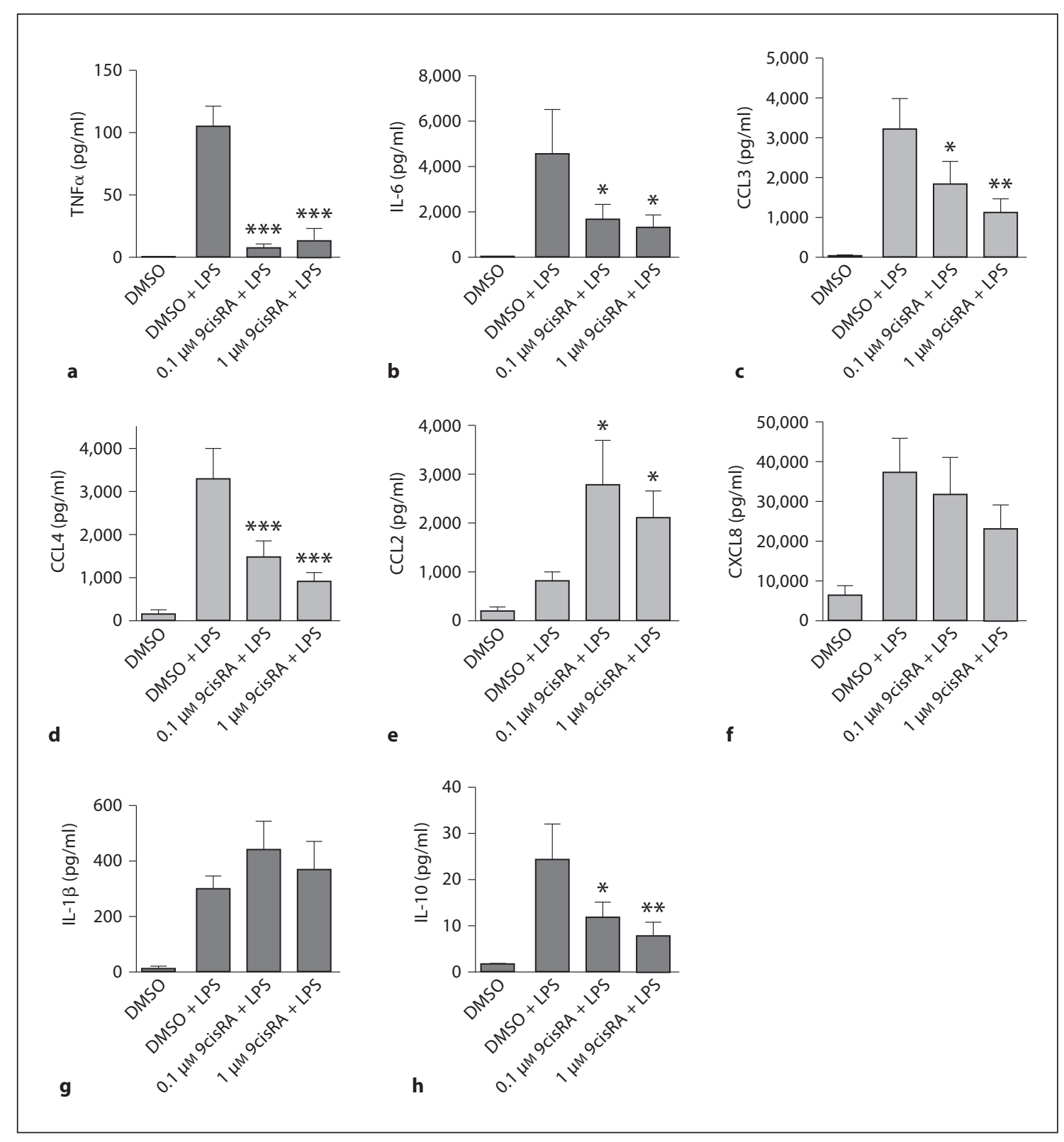

Fig. 2. 9cisRA inhibits the release of several LPS-induced cytokines and chemokines but induces CCL2 production. Cultures of adherent human monocytes from 5 separate donors were pretreated for $1 \mathrm{~h}$ with 9cisRA or DMSO (0.1\%, control), followed by stimulation with LPS $(1 \mu \mathrm{g} / \mathrm{ml})$. Six hours later, cell culture media were harvested and analyzed for cytokines and chemokines by luminex assay. a-g Mean levels \pm SD of proinflammatory cytokines and chemokines. h Anti-inflammatory cytokine IL-10. ${ }^{*} \mathrm{p}<0.05,{ }^{* *} \mathrm{p} \leq 0.01,{ }^{* * *} \mathrm{p} \leq 0.001$.

when 9cisRA $(1 \mu \mathrm{M})$ was combined with GW3965 (LXR agonist, $0.3 \mu \mathrm{M})$ (data not shown).

\section{atRA and 9cisRA Both Upregulate CCL2}

9cisRA may function as an agonist of both RXR and RAR. It has previously been posted that atRA, which is a specific RAR agonist, reduces the mRNA levels of CCL2 in the monocyte cell line U937 [18]. Since we found 9 cisRA to have the opposite effect in our studies and since 9 cisRA and atRA may act as competing agonists of the same nuclear receptor, we compared their effect on CCL2 in human primary cells. 9cisRA and atRA $(0.1$ or $1.0 \mu \mathrm{M})$ 


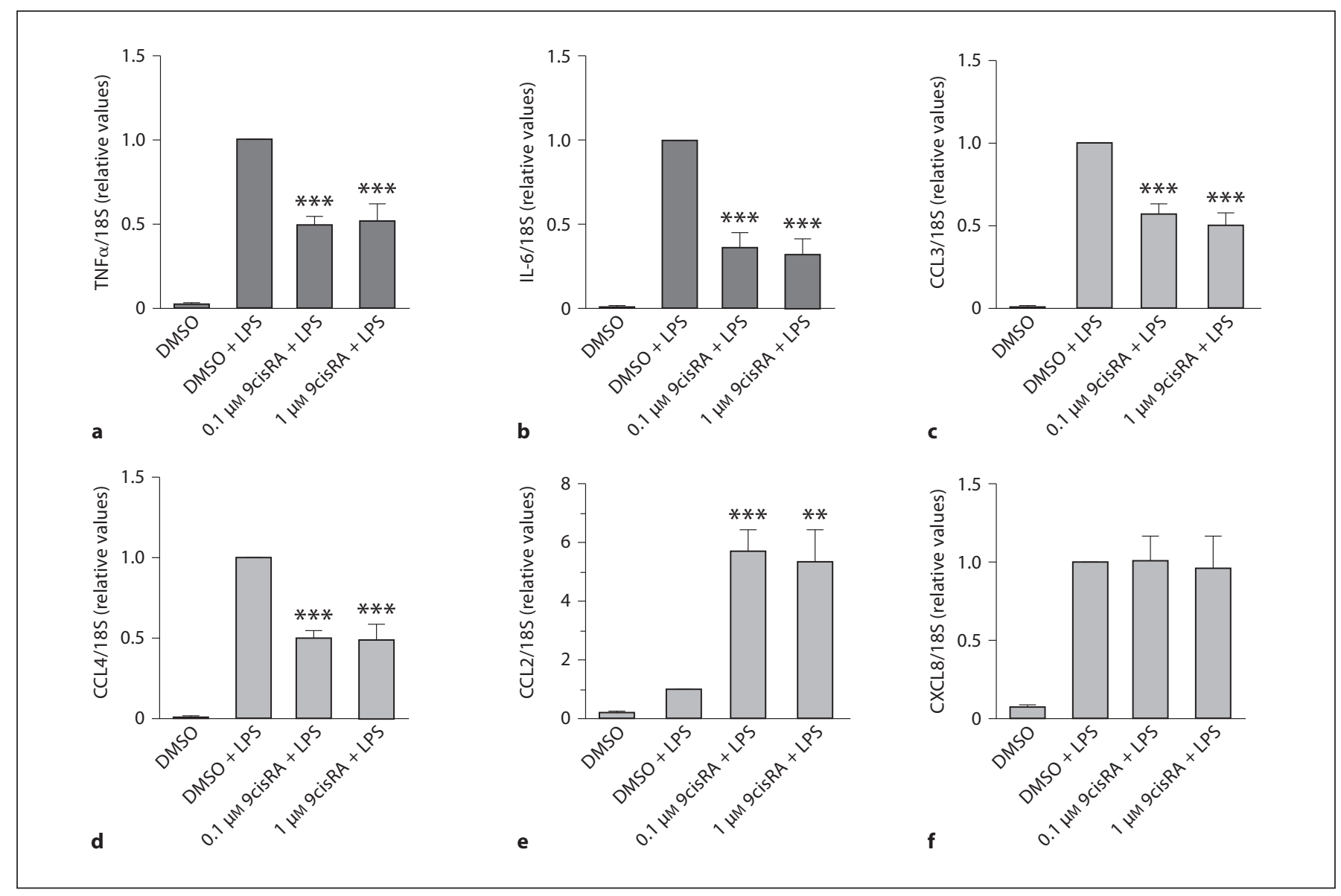

Fig. 3. 9cisRA inhibits LPS-induced cytokine and chemokine mRNA but induces CCL2. DMSO (0.1\%, control) or 9cisRA were added to cultures of adherent human monocytes from 5 separate donors $1 \mathrm{~h}$ before stimulation with LPS $(1 \mu \mathrm{g} / \mathrm{ml})$. The cells were then incubated for $2 \mathrm{~h}$, and total RNA was isolated and analyzed by quantitative PCR. a-f Relative levels normalized for 18S rRNA. Levels after exposure to LPS alone were set to 1 for each donor. ${ }^{* *} \mathrm{p} \leq 0.01 .{ }^{* * *} \mathrm{p} \leq 0.001$. showed the same trend in inducing CCL2 in our experiments (fig. 5), albeit that only 1- $\mu \mathrm{M} 9$ cisRA significantly induced LPS-mediated CCL2 release.

\section{Treatment of Adherent Monocytes by 9cisRA Induces}

Migration of CD14high Monocytes

The finding that CCL2 production by human monocytes is increased when the cells are pretreated with 9cisRA and atRA made us eager to investigate the potential that 9cisRA- and atRA-treated cells may have on the migration of CCL2-sensitive monocytes. Transwell chemotaxis of monocytes towards conditioned media from cells that were incubated with either 9cisRA, atRA, LPS or DMSO (control) for $6 \mathrm{~h}$ was assessed by flow cytometry. Figure 6 a shows that monocytes are recruited significantly towards conditioned media from cells treated with 9cisRA, compared to conditioned media from cells cultured with DMSO or LPS. The same tendency, although not significant, was shown for atRA. The CCL2, CCL3, CCL4, TNF $\alpha$, IL-1 $\beta$ and IL- 6 levels in the conditioned media were quantified by a luminex assay, and results show that CCL4 (fig. 6e), TNF $\alpha$ (fig. 6f) and IL-6 (fig. 6h) were significantly upregulated only when LPS was added. CCL3 (fig. 6d) and IL-1 $\beta$ (fig. 6g) also tended to be upregulated by LPS. The CCL2 level (fig. 6c) tended to increase only in the supernatants from cells stimulated by retinoic acids. To test whether CCL2 alone could promote chemotaxis of the human monocytes, we induced chemotaxis towards media containing 10,100 or 1,000 $\mathrm{ng} / \mathrm{ml}$ recombinant CCL2 (fig. 6b). We found a bellshaped migration curve, with a significant migration towards $100 \mathrm{ng} / \mu \mathrm{l} \mathrm{CCL} 2$ only (fig. 6b). We measured mean 
Fig. 4. No effects of 9cisRA on protein kinases were involved in LPS signaling. Cultures of human adherent monocytes from 5 separate donors were exposed to LPS $(1 \mu \mathrm{g} / \mathrm{ml})$ or saline, following a 1-hour pretreatment by 9 cisRA $(1 \mu \mathrm{M})$ or DMSO. The cells were harvested and lysed after 20 min. Levels of intracellular phosphoproteins and total proteins were measured by a multiplex luminex assay. Data are presented as the amount of phosphorylated signaling proteins ( $\mathrm{p}-\mathrm{X}$ ) divided by the total number of signaling proteins (tot-X) present. a-d Levels from cells treated with DMSO alone $(0.1 \%$, negative control) were set to 1 . A p value of $\leq 0.05$ was considered a significant difference.

Fig. 5. CCL2 tends to be induced by both 9cisRA and atRA in combination with LPS stimulation. Cultured human adherent monocytes from 5 separate donors were exposed to saline or LPS $(1 \mu \mathrm{g} / \mathrm{ml})$ alone or after a 1-hour pretreatment with 9cisRA, atRA or DMSO (control). After $6 \mathrm{~h}$, the supernatants were harvested. The level of CCL2 was measured using a Flow Cytomix bead-based assay. ${ }^{*} \mathrm{p} \leq 0.05$.
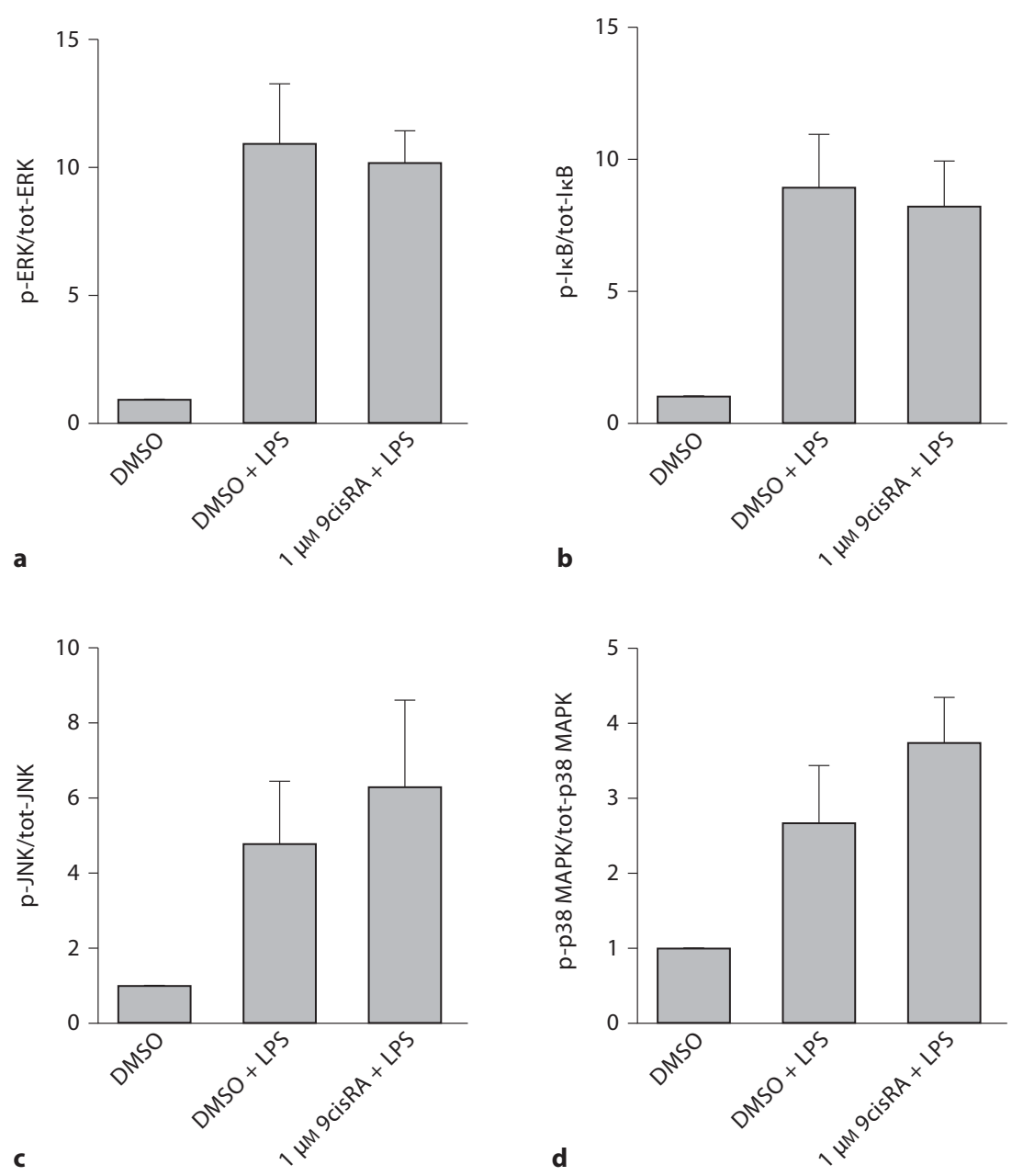

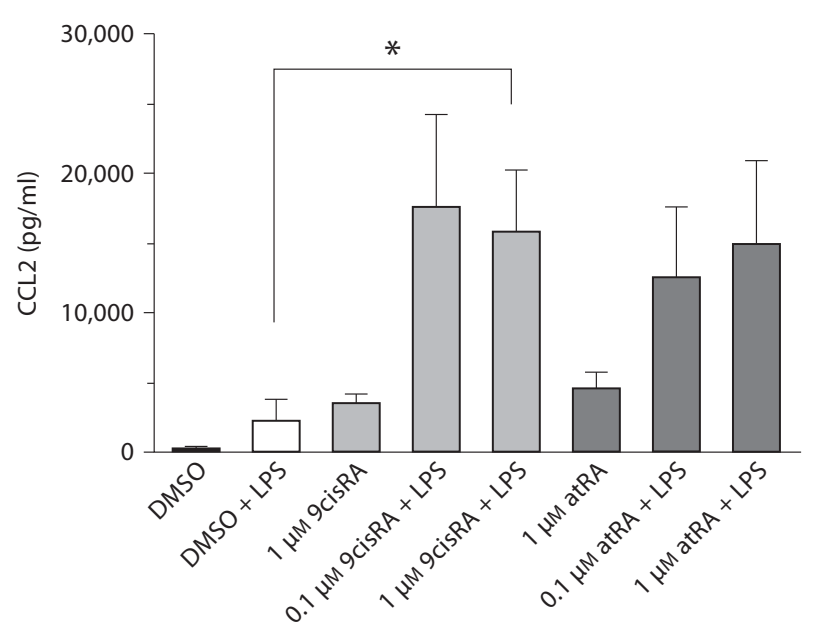




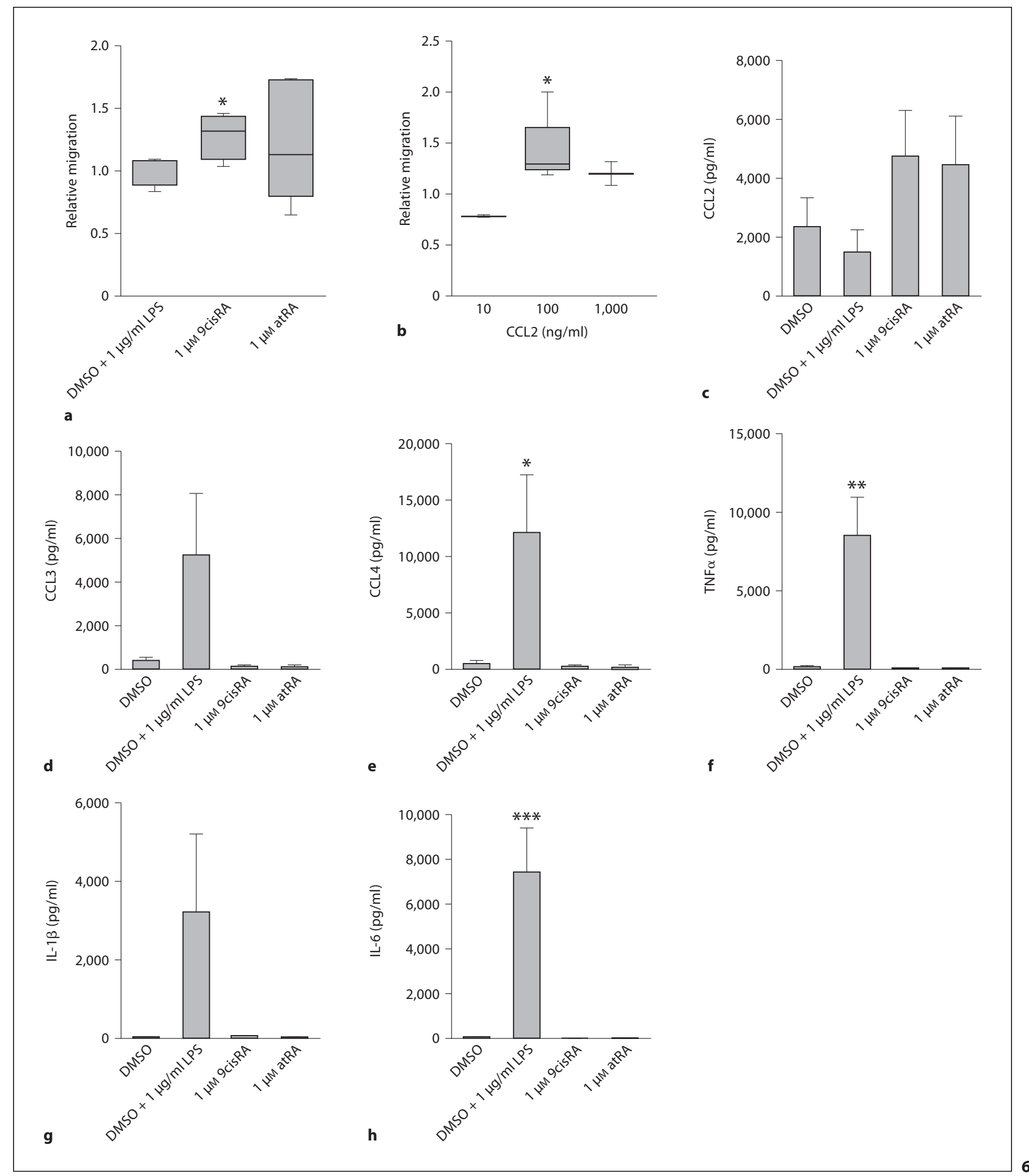

(For legend see next page.) 
CCL2 levels of about $5 \mathrm{ng} / \mathrm{ml}$ in the conditioned media, indicating that CCL 2 may be involved, but is probably not the only chemokine responsible for increased chemotaxis. CCL3 and CCL4, which also function as monocyte attractants, were decreased by 9cisRA.

A test of CCL2 blocking, with the CCL2-blocking antibody $2 \mathrm{H} 5(20 \mu \mathrm{g} / \mathrm{ml}$, AH diagnostics) used as reported [19], revealed a blocking of cell migration towards the conditioned media from 1 out of 3 donors (two migration experiments performed per donor, data not shown), indicating donor variations and that, in addition to CCL2, other chemokines are likely to be involved.

\section{Discussion}

In vitamin A deficiency, increased systemic inflammation along with a decreased capacity to eradicate infection is described, effects that may be counteracted by vitamin A supplements [4]. Freshly isolated and adhered primary human monocytes present an attractive model to facilitate the study of immediate human monocyte responses. We show that the adherent monocytes in our study are strongly enriched in the CD14dimCD16+ monocyte subset. This subset, which represents only about $10 \%$ of the total monocyte population in healthy human blood, is shown to be strongly increased in acute inflammatory conditions like sepsis, autoimmune diseases like rheumatoid arthritis and diabetes and in conditions accompanied by chronic pain [20-22]. It has also been proposed that CD14dimCD16+ monocytes develop from classical CD14high monocytes [23] and exhibit a greater ability to adhere to endothelium [24]. Our data indicate that isolating adherent monocytes may be a simple way of strongly enriching the CD14dimCD16+ mono-

Fig. 6. Stimulation of adherent monocytes by 9cisRA increases their ability to induce migration of classical monocytes. Adherent monocytes isolated from 7 separate donors were treated with 9cisRA $(1 \mu \mathrm{M})$, atRA $(1 \mu \mathrm{M})$, DMSO $(0.1 \%$ control) or LPS $(1 \mu \mathrm{g} / \mathrm{ml})$ for $6 \mathrm{~h}$. The conditioned media from the adherent monocytes were used for assaying migration of nonadherent monocytes from 5 different donors, through 5 - $\mu \mathrm{m}$ transwell filters. Migrated cells were counted by flow cytometry. Relative migration towards the conditioned media from adherent monocytes (a) or towards medium containing doses of $10 \mathrm{ng} / \mathrm{ml}(\mathrm{n}=2), 100$ $\mathrm{ng} / \mathrm{ml}(\mathrm{n}=5)$ and $1,000 \mathrm{ng} / \mu \mathrm{l}(\mathrm{n}=2)$ of recombinant human CCL2 (b). c-h Levels of CCL2, CCL3, CCL4, TNF $\alpha$, IL-1 $\beta$ and IL- 6 in the conditioned media were measured by luminex assay. ${ }^{*} \mathrm{p} \leq$ $0.05,{ }^{* *} \mathrm{p} \leq 0.01$ - relative to control (DMSO). cyte population in vitro. CD14dimCD16+ monocytes have been demonstrated to be particularly inflammatory and to be effective producers of TNF $\alpha$, while partly deficient in the production of anti-inflammatory IL-10 [25, 26]. Our data clearly show that 9 cisRA has a significant inhibitory effect on the production of TNF $\alpha$ and other central proinflammatory cytokines and chemokines in adherent monocytes, a regulation occurring at the transcriptional level. It has previously been reported that 9 cisRA changes the inflammatory mediator release of the human monocyte cell line U937 [16], primary mouse microglia, astrocytes and splenic macrophages $[15,17]$, as well as murine myelin basic protein-specific T cells [27]. We also found that 9cisRA inhibits IL-10 production, but that the IL-10 level produced by the adherent monocytes in response to LPS after $6 \mathrm{~h}$ is low $(20-30 \mathrm{pg} / \mathrm{ml})$. Whereas normal IL-10 plasma levels range from 0.2 to $10 \mathrm{pg} / \mathrm{ml}$, the commonly used IL-10 levels for studying the anti-inflammatory effects in in vitro assays are in the 1-10 ng/ $\mathrm{ml}$ range [28]. However, IL-10 may increase over time. 9cisRA is reported to bind all three isoforms of RXR $(\operatorname{RXR} \alpha, \beta$ and $\gamma)[29,30]$. In human monocytes, $\operatorname{RXR} \alpha$ is the dominating isoform, and the dominating RXR partners are RAR $\alpha, V D R, L X R \alpha, L X R \beta$ and PPAR $\delta$ [31].

The 9cisRA-mediated reduction of proinflammatory mediator production that we observed at the mRNA level corresponds well with effects on protein release, with an exception for TNF $\alpha$. Interestingly, the release of TNF $\alpha$ protein was affected more strongly by 9cisRA compared to TNF $\alpha$ mRNA expression, suggesting that regulation at the posttranscriptional level also may also be involved.

Several studies suggest that vitamin A deficiency causes increased inflammation, most likely mediated by macrophages $[5,32]$, and one of these studies showed that vitamin A supplementation led to an attenuation of TNF $\alpha$ in serum and whole blood ex vivo [33]. Even though vitamin A deficiency enhanced the proinflammatory response, it is also reported that a deficiency causes an impaired host response by reducing the phagocytic capacity in rat peritoneal macrophages [6]. Together, these data suggest that complications related to infection may increase in severity in vitamin A-deficient subjects, along with an increased systemic inflammatory response.

In 2008, Lee et al. [34] found that inhibition of NFKBdependent genes by activating RXR with 9cisRA involved direct antagonism of NFKB signaling in a bronchial epithelial cell line. The same year, Austenaa et al. [16] concluded that atRA inhibits LPS-induced NFKB activation in mice in vivo and in the human cell line U937. The pro- 
totypical proinflammatory transcription factor $\mathrm{NF \kappa B}$ plays an essential role in conveying the innate response to endotoxins and cytokines [35]. In our study, we found no effect of 9cisRA pretreatment on the LPS-mediated phosphorylation/activation of I $\mathrm{B}, \mathrm{ERK}, \mathrm{JNK}$ and p38 MAPK within the initial 20 min after LPS stimulation. As IкB phosphorylation precedes the nuclear translocation and activation of $\mathrm{NF \kappa B}$, our results indicate that the effect of 9cisRA on NFKB found by others is regulated downstream of IкB phosphorylation. Studies in human monocyte cell lines and epithelial cell lines find inhibition of NFкB within the nucleus, possibly at the target promoters. Ko et al. [36] reported in 2007 that 9cisRA in the absence of LPS induces both MAPK and ERK activation in the human monocyte cell line THP-1 peaking at $2 \mathrm{~h}$. We did not observe such effects in primary monocytes in our experiments (data not shown), after the 1-hour pretreatment by 9 cisRA. We did not check for further long-term effects.

Although the inflammatory monocyte chemoattractants CCL3 and CCL4 were also significantly attenuated by 9cisRA in our experiments, we found a strong upregulation of CCL2 by 9cisRA. Although other monocyte chemoattractants exist and may be relevant, this switch from CCL3/CCL4 to CCL2 indicates a shift in monocyte attraction based on chemokine receptor expression, from the CCL3/CCL4 receptor CCR5 to the CCL2 receptor CCR2. In the in vivo situation, CCL2 is upregulated at sites of infection and participates in the regulation of migration and infiltration of monocytes and macrophages [37]. In such acute situations it is important to have an effective recruitment of immune cells to the foci of infection, in order to control pathogens. However, high concentrations of CCL2 are also correlated with chronic inflammatory conditions like inflammatory bowel disease, allergic asthma and rheumatoid arthritis, where the function and importance of CCL2 is more obscure [37]. Interestingly, whereas classical CD14high monocytes express the CCL2 receptor CCR2, adherent monocytes have been reported to not express this chemokine receptor and are not likely to migrate in response to CCL2 [38].

Activation of RAR may be stimulated by both 9cisRA and atRA [29]. It has been reported that atRA downregulates CCL2 in the human monocyte cell line U937 [16]. When we tested this in adherent human monocytes, we found no difference in the effects of 9 cisRA and atRA on CCL2. Induction of CCL2 by 9cisRA has previously been demonstrated in the monocyte cell line THP-1 [39], and another study performed in acute promyelocytic leukemia (APL) cells and alveolar cells shows that the secretion of CCL2 is enhanced by atRA treatment in both cell types, in line with our results [40]. Upregulation of CCL2 by atRA has also previously been reported in APL cells [41]. In the study by Tsai et al. [40], upregulation of CCL2 production in the lung cells caused an enhanced transmigration of APL cells towards alveolar epithelial cells, indicating that CCL2 plays an important role in the acute respiratory distress syndrome caused by atRA treatment in patients with APL. In a situation with a local infectious focus as the triggering factor, monocytes that have adhered and translocated to the site of infection may use a similar mechanism to increase the influx of monocytes to the region. In our study we find that conditioned media from adherent monocytes treated with 9cisRA increased the migration of classical CD14high monocytes. CCL2 is a candidate for the increased migration observed, but it is not the only candidate. We did not succeed in obtaining clear results by blocking CCL2, nor did we obtain equal migration efficiency with similar doses of recombinant CCL2, indicating that other monocyteattracting chemokines may be expressed in the conditioned media from adherent monocytes exposed to 9cisRA and may be involved in inducing migration.

We conclude from this work that 9cisRA can act as a potent modulator of the inflammatory response of primary human adherent monocytes, dominated by the CD14dimCD16+ inflammatory monocyte subset. 9cisRA treatment also led to the ability to induce migration of classical monocytes. The loss of this retinoic acidinduced activity may, at least in part, contribute to some of the complications observed in vitamin A-deficient patients.

\section{Acknowledgments}

We thank Grethe Dyrhaug and Signe Flood-Kjeldsen at the Institute for Surgical Research, Oslo University Hospital, and Margareth Tamburstuen and Aina Lian at the Institute of Clinical Dentistry, University of Oslo, for their skilled technical assistance.

References

1 Tracey KJ: The inflammatory reflex. Nature 2002;420:853-859.

-2 Rittirsch D, Flierl MA, Ward PA: Harmful molecular mechanisms in sepsis. Nat Rev Immunol 2008;8:776-787.

-3 Alberti C: Epidemiology of sepsis and infection in ICU patients from an international multicentre cohort study. Intensive Care Med 2002;28:108-121. 
4 Stephensen CB: Vitamin A, infection, and immune function. Annu Rev Nutr 2001;21: 167-192.

$\checkmark 5$ Wiedermann U, Chen XJ, Enerback L, Hanson LA, Kahu H, Dahlgren UI: Vitamin A deficiency increases inflammatory responses. Scand J Immunol 1996;44:578-584.

6 Wiedermann U, Tarkowski A, Bremell T, Hanson LA, Kahu H, Dahlgren UI: Vitamin A deficiency predisposes to Staphylococcus aureus infection. Infect Immun 1996;64: 209-214.

7 Ziouzenkova O, Plutzky J: Retinoid metabolism and nuclear receptor responses: new insights into coordinated regulation of the PPAR-RXR complex. FEBS Lett 2008;582: 32-38.

-8 Levin AA, Sturzenbecker LJ, Kazmer S, Bosakowski T, Huselton C, Allenby G, Speck J, Kratzeisen C, Rosenberger M, Lovey A: 9-cis retinoic acid stereoisomer binds and activates the nuclear receptor RXR alpha. Nature 1992;355:359-361.

9 Allenby G, Bocquel MT, Saunders M, Kazmer S, Speck J, Rosenberger M, Lovey A, Kastner P, Grippo JF, Chambon P: Retinoic acid receptors and retinoid $\mathrm{X}$ receptors: interactions with endogenous retinoic acids. Proc Natl Acad Sci USA 1993;90:30-34.

-10 Myhre AE, Agren J, Dahle MK, Tamburstuen MV, Lyngstadaas SP, Collins AJ, Foster SJ, Thiemermann C, Aasen AO, Wang JE: Liver $\mathrm{X}$ receptor is a key regulator of cytokine release in human monocytes. Shock 2008;29: 468-474.

11 Castrillo A, Tontonoz P: Nuclear receptors in macrophage biology: at the crossroads of lipid metabolism and inflammation. Annu Rev Cell Dev Biol 2004;20:455-480.

$\checkmark 12$ Lefebvre P, Benomar Y, Staels B: Retinoid $\mathrm{X}$ receptors: common heterodimerization partners with distinct functions. Trends Endocrinol Metab 2010;21:676-683.

13 Desvergne B: RXR: from partnership to leadership in metabolic regulations. Vitam Horm 2007;75:1-32.

-14 Zhang XK, Lehmann J, Hoffmann B, Dawson MI, Cameron J, Graupner G, Hermann T, Tran P, Pfahl M: Homodimer formation of retinoid $\mathrm{X}$ receptor induced by 9 -cis retinoic acid. Nature 1992;358:587-591.

$\checkmark 15 \mathrm{Xu}$ J, Drew PD: 9-Cis-retinoic acid suppresses inflammatory responses of microglia and astrocytes. J Neuroimmunol 2006;171:135144.

-16 Austenaa LM, Carlsen H, Hollung K, Blomhoff HK, Blomhoff R: Retinoic acid dampens LPS-induced NF-kappaB activity: results from human monoblasts and in vivo imaging of NF-kappaB reporter mice. J Nutr Biochem 2009;20:726-734.
17 Na SY, Kang BY, Chung SW, Han SJ, Ma X, Trinchieri G, Im SY, Lee JW, Kim TS: Retinoids inhibit interleukin-12 production in macrophages through physical associations of retinoid X receptor and NFkappaB. J Biol Chem 1999;274:7674-7680.

18 World Medical Association Declaration of Helsinki: ethical principles for medical research involving human subjects: JAMA 2000;284:3043-3045.

19 Luo Y, Laning J, Hayashi M, Hancock PR, Rollins B, Dorf ME: Serologic analysis of the mouse beta chemokine JE/monocyte chemoattractant protein-1. J Immunol 1994; 153:3708-3716.

20 Ziegler-Heitbrock L: The CD14+ CD16+ blood monocytes: their role in infection and inflammation. J Leukoc Biol 2007;81:584592.

21 Fingerle G, Pforte A, Passlick B, Blumenstein M, Strobel M, Ziegler-Heitbrock HW: The novel subset of CD14+/CD16+ blood monocytes is expanded in sepsis patients. Blood 1993;82:3170-3176.

22 Ritz BW, Alexander GM, Nogusa S, Perreault MJ, Peterlin BL, Grothusen JR, Schwartzman RJ: Elevated blood levels of inflammatory monocytes (CD14+ CD16+) in patients with complex regional pain syndrome. Clin Exp Immunol 2011;164:108-117.

23 Ziegler-Heitbrock HW: Heterogeneity of human blood monocytes: the CD14+ CD16+ subpopulation. Immunol Today 1996;17: 424-428.

24 Ramirez R, Carracedo J, Merino A, Soriano S, Ojeda R, Alvarez-Lara MA, Martin-Malo A, Aljama P: CD14+CD16+ monocytes from chronic kidney disease patients exhibit increased adhesion ability to endothelial cells. Contrib Nephrol 2011;171:57-61.

25 Belge KU, Dayyani F, Horelt A, Siedlar M Frankenberger M, Frankenberger B, Espevik T, Ziegler-Heitbrock L: The proinflammatory CD14+CD16+DR++ monocytes are a major source of TNF. J Immunol 2002;168 3536-3542.

26 Frankenberger M, Sternsdorf T, Pechumer H, Pforte A, Ziegler-Heitbrock HW: Differential cytokine expression in human blood monocyte subpopulations: a polymerase chain reaction analysis. Blood 1996;87:373377.

27 van NS, Kampmann E, Mey J: RAR/RXR and PPAR/RXR signaling in neurological and psychiatric diseases. Prog Neurobiol 2008;85:433-451.

28 Murray PJ: The primary mechanism of the IL-10-regulated anti-inflammatory response is to selectively inhibit transcription. Proc Natl Acad Sci USA 2005;102:86868691

-29 Allenby G, Bocquel MT, Saunders M, Kazmer S, Speck J, Rosenberger M, Lovey A, Kastner P, Grippo JF, Chambon P: Retinoic acid receptors and retinoid $\mathrm{X}$ receptors: interactions with endogenous retinoic acids Proc Natl Acad Sci USA 1993;90:30-34.
30 Allenby G, Janocha R, Kazmer S, Speck J, Grippo JF, Levin AA: Binding of 9-cis-retinoic acid and all-trans-retinoic acid to retinoic acid receptors alpha, beta, and gamma. Retinoic acid receptor gamma binds alltrans-retinoic acid preferentially over 9-cisretinoic acid. J Biol Chem 1994;269:1668916695.

31 Szeles L, Poliska S, Nagy G, Szatmari I, Szanto A, Pap A, Lindstedt M, Santegoets SJ, Ruhl R, Dezso B, Nagy L: Research resource: transcriptome profiling of genes regulated by RXR and its permissive and nonpermissive partners in differentiating monocyte-derived dendritic cells. Mol Endocrinol 2010; 24:2218-2231.

32 Shams NB, Reddy CV, Watanabe K, Elgebaly SA, Hanninen LA, Kenyon KR: Increased interleukin-1 activity in the injured vitamin Adeficient cornea. Cornea 1994;13:156-166.

33 Aukrust P, Muller F, Ueland T, Svardal AM, Berge RK, Froland SS: Decreased vitamin A levels in common variable immunodeficiency: vitamin A supplementation in vivo enhances immunoglobulin production and downregulates inflammatory responses. Eur J Clin Invest 2000;30:252-259.

\$3 Lee HC, Headley MB, Iseki M, Ikuta K, Ziegler SF: Cutting edge: inhibition of NFkappaB-mediated TSLP expression by retinoid X receptor. J Immunol 2008;181:5189_5193.

35 Lawrence T: The nuclear factor NF-kappaB pathway in inflammation. Cold Spring Harb Perspect Biol 2009; 1:a001651.

$>36$ Ko J, Yun CY, Lee JS, Kim JH, Kim IS: p38 MAPK and ERK activation by 9-cis-retinoic acid induces chemokine receptor CCR1 and CCR2 expression in human monocytic THP-1 cells. Exp Mol Med 2007;39:129-138.

37 Deshmane SL, Kremlev S, Amini S, Sawaya BE: Monocyte chemoattractant protein-1 (MCP-1): an overview. J Interferon Cytokine Res 2009;29:313-326.

38 Tacke F, Randolph GJ: Migratory fate and differentiation of blood monocyte subsets. Immunobiology 2006;211:609-618.

-39 Zhu L, Bisgaier CL, Aviram M, Newton RS: 9-cis retinoic acid induces monocyte chemoattractant protein-1 secretion in human monocytic THP-1 cells. Arterioscler Thromb Vasc Biol 1999;19:2105-2111.

40 Tsai WH, Shih CH, Lin CC, Ho CK, Hsu FC, Hsu HC: Monocyte chemotactic protein-1 in the migration of differentiated leukaemic cells toward alveolar epithelial cells. Eur Respir J 2008;31:957-962.

-41 Shibakura M, Niiya K, Niiya M, Asaumi N, Yoshida C, Nakata Y, Tanimoto M: Induction of CXC and CC chemokines by all-trans retinoic acid in acute promyelocytic leukemia cells. Leuk Res 2005;29:755-759. 